\title{
Profile of Mass Casualties of Animal Bite Cases Reported to a Tertiary Care Institution from April 2014 to March 2015 in North Kerala : India
}

\author{
Lathika Velichapatt Ramakrishnan', Lilabi Shakir², Priya Chandran², Jayakrishnan Thavody²
}

Lathika Velichapatt Ramakrishnan', Lilabi Shakir ${ }^{2}$, Priya Chandran², Jayakrishnan Thavody² 'Department of Community Medicine, Government Medical college, Kozhikode, INDIA.

${ }^{2}$ Department of Community Medicine, Government Medical College, Kozhikode, INDIA.

\section{Correspondence \\ Dr. M. P Lilabi Shakir}

Associate Professor, Department of Community Medicine, Government Medical College, Kozhikode, INDIA. Ph.no: 09446386993

E-mail address: drlailashakir@gmail.com

\section{History}

- Submission Date: 25-06-16

- Revised Date: 18-11-16

- Accepted Date: 02-01-17

DOI : 10.5530/ijmedph.2017.1.5

Article Available online

http://www.ijmedph.org/v7/i1

\section{Copyright}

(C) 2017 Phcog.Net. This is an openaccess article distributed under the terms of the Creative Commons Attribution 4.0 International license.

\begin{abstract}
Background: Animal bite is an emerging Public health problem causing injuries and even death. Increase incidences of dog bite have been reported from the Indian state of Kerala from last two years and there have been several instances of a single animal biting several victims at the same area. The preventive clinic of Calicut Medical College is a referral centre for the management of animal bite cases in North Kerala. Incidents of mass casualties are a source of panic and alarm among public. The present study analyses these incidents of mass casualties of animal bites studying the epidemiological profile of animals involved. Considering the paucity of studies in this area the information obtained from the present study may help in mapping risk areas and to take necessary control measures. Objectives: To find out the epidemiological and clinical profile of mass casualty due to animal bites reported to the institution. Methodology: Record based cross sectional study design. Review of the mass casualty register maintained at the Preventive Clinic. Details of animal bite cases treated in the clinic from 2014 April to 2015 March were collected. Sociodemographic characteristics, clinical profile and management details were analyzed. Results: A total of 7072 animal bite cases reported to the preventive clinic during the study period .Of this, there were 54 incidents of mass casualty involving 236 patients were registered to receive treatment in the clinic. Majority were males (53\%). Adults (79.2\%) were commonly effected than children (20.8\%).Median age was found to be $36 y$ rs . Exposure to dogs constituted $77.1 \%$ of cases, followed by fox (11.9\%). All were category 3 wounds and were given anti rabies vaccine, anti rabies immunoglobulin and antibiotics. Conclusion: There were 54 incidents of animal bite mass causalities involving 236 people. Dogs were the commonest animal causing mass casualty. Control of stray dog population by animal birth control needed.
\end{abstract}

Key words: Animal bite, Epidemiological, Clinical profile, Mass casualty, Mapping, Risk areas.

\section{INTRODUCTION}

Animal bite Create fear among people especially when it is bitten by a stray dog or suspected rabid animal. Studies have shown that one in 200 visit in emergency department is due to dog bite. ${ }^{1}$ Patient presenting to the emergency departments with bite injuries are of severe in nature and many people may be bitten when the animal involved was suffering from rabies.

A mass casualty incident or sometimes called a multiple-casualty incident or multiple-casualty situation is any incident in which emergency medical services resources, such as personnel and equipment, are overwhelmed by the number and severity of casualties. Though classically mass casualties are associated with traffic accidents, disasters or armed attacks instances of a single animal biting several people within the same time period have been observed in many developing countries .In short a Mass Casualty Incident (MCI) can be defined as an incident that has produced more casualties than a customary response

Cite this article : Ramakrishnan LV, Shakir L, Chandran P, Thavody J. Profile of Mass Casualties of Animal Bite Cases Reported to a Tertiary Care Institution from April 2014 to March 2015 in North Kerala : India. Int J Med. Public Health. 2017; 7(1): 33-7 
Table 1: Age wise distribution

\begin{tabular}{|ccc|}
\hline Age group in years & N & $\%$ \\
\hline Below 15 & 63 & 22.7 \\
\hline $15-65$ & 148 & 62.7 \\
Above 65 & 25 & 10.6 \\
& 236 & 100 \\
\hline
\end{tabular}

\section{Mass Casualty incidents}

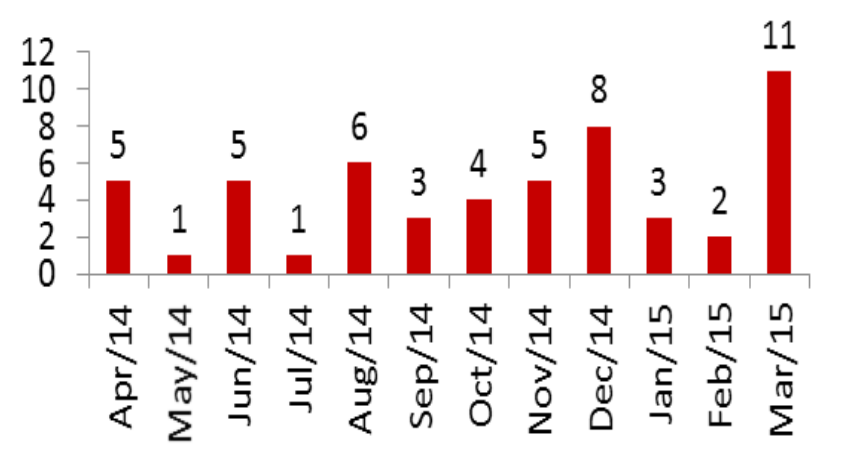

Figure 1: Mass casualty incidents.

humans. Every year more than 15 million people world wide receive a post bite vaccination and this prevent thousands of death annually

India is reported to have the highest incidence of rabies globally. ${ }^{3}$ Based on available evidence, a fair estimate of rabies burden in India is 2.74 rabies cases per 100000 people annually. In India, dogs are responsible for about $97 \%$ of human rabies, followed by cats $(2 \%)$, jackals, mongoose and others (1\%).

A multicentre study in India in 2003 showed that 20,565 human deaths occur annually. Most cases are reported in rural communities where no large-scale dog vaccination programmes have been conducted and where the incidence of dog rabies remains high. ${ }^{4}$ While the availability of post-exposure prophylaxis has improved, it is not clear how much rural communities have benefited; furthermore, most deaths occur among people who do not seek medical care. ${ }^{5}$

A single Rabid dog is capable of biting a large number of humans, animals and may involve an area of over $40 \mathrm{~km}$ in its short span of clinical illness. Mass casualties cause panic and alarm among public and strain on existing resources. It is also a reason for burden on the health services wherein a large quantities of vaccine and serum may be needed at short notice which might cause difficulty in meeting the demand of vaccine in rural areas.

In Kerala recently there is a drastic increase in dog bite cases due to alarming rise in stray dog population as a consequence of ban on culling of stray dogs. Daily media reports itself explains mass casualties due to animal bite mainly of stray dogs and other animals like fox or bite affected domestic animals. So the analysis of mass casualties may help to find out the pattern of animal involved also to know the epidemiological profile and mapping of the area where rabid animal were reported .This information will be helpful to take necessary control measures. There is a dearth of studies on similar topics. This study help to assess the problem of animal bite casualties and mapping area or place of risk for rabies and also help the authority to improve the patient care by procuring anti rabies vaccine and immunoglobulin.

\section{Gender}

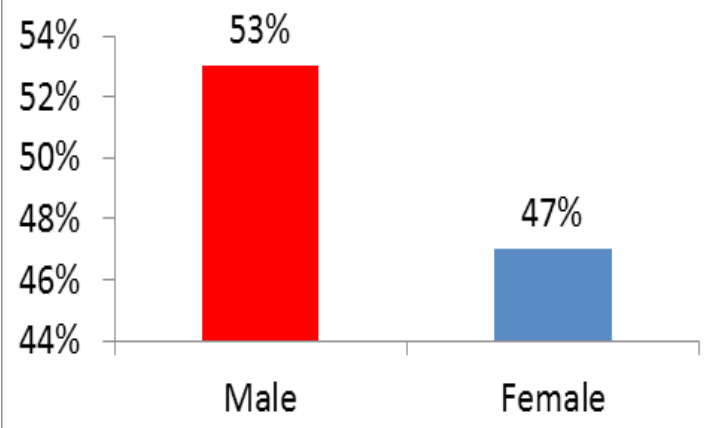

Male

Female

Figure 2: Sex wise distribution.

\section{MATERIALS AND METHODS}

A Record based descriptive study was conducted in Preventive Clinic, Kozhikode Govt. Medical College, a tertiary care centre in North KeralaIndia. The study period was one year ( April 2014 to March 2015). The Preventive clinic under the Department of Community Medicine provide $24 \times 7$ services for animal bite. In addition to the daily OP register, a separate mass casualty register is being maintained at the clinic for recording the details of the mass casualties like sociodemographic characteristics, injury details of each patient, details of the animal that caused the injury/bite, behaviour, stray or domestic. The date and time of the incidents, the details of the animal involved and the clinical details of the patients undergoing treatment are entered in this register. After getting prior permission from medical officer in charge of Preventive clinic and Head of department of Community Medicine case details were collected from the mass causality register maintained at the clinic from 2014 April to 2015 March. We follow an operational definition for mass casualty as more than two persons bitten by the same animal at the same day from a same or nearby villages . Sociodemographic details, clinical profile and management details were analyzed. Data was analyzed with SPSS version 18 .

\section{Inclusion criteria}

All animal bite cases from same locality where more than two persons were bitten by same animal on same day.

\section{Exclusion criteria}

Isolated animal bite cases reporting to Preventive clinic or casualty from a locality on different days.

\section{Ethical Issue}

The study was conducted after obtaining permission from Institutional ethics committee Govt Medical College Kozhikode and Medical Officer in charge of Preventive clinic. 


\section{Table 2: Site of Bite}

\begin{tabular}{|ccc|}
\hline Site & No & $\%$ \\
\hline Lower limb & 135 & 57.2 \\
Upper limb & 57 & 24.2 \\
Trunk & 11 & 4.7 \\
Head \&neck & 13 & 5.5 \\
Others & 20 & 8 \\
Total & 236 & 100 \\
\hline
\end{tabular}

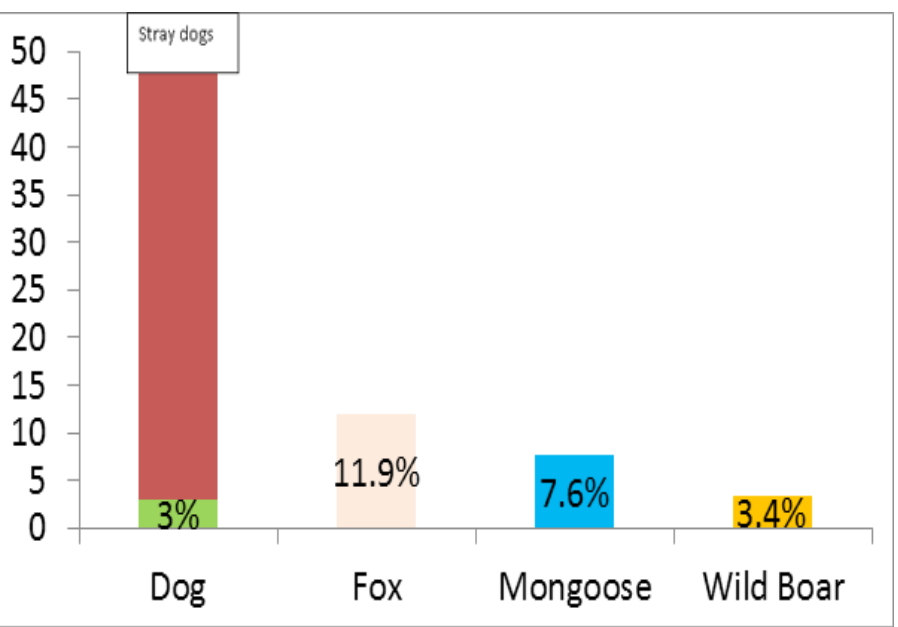

Figure 3: Type of animals.

\section{RESULTS AND DISCUSSION}

A study on clinical profile of animal bite mass casualties revealed that a total of 7072 patients had been reported in the Preventive Clinic due to animal bite during the study period.There were 54 incidents of mass casualties and 236 (3.3\%) people were involved in mass casualty.

Minimum number of people involved per animal was 3 and maximum number of people involved per animal was 27. The mean number of person bitten per animal was found to be 5.6 and a standard deviation of \pm 2.4 . Maximum number of people bitten were from Koyilandi area (27 cases) and incidents with more than 10 people involved were Mepayur (24 cases), Baypore (17 cases), Vatakara (14 cases), Perambra (11 cases) and Thalassery (10 cases).

\section{Age}

The age of the study population ranges from 6 months to 88 years and the median age was found to be 36 years. $26 \%$ of the people involved in the mass casualty were children less than 14 years and $74 \%$ belong to the age 15 to 88 years (Table 1 ).

Ni M Susilawathi ${ }^{9}$ et al also reported a mean age of 36.6 years (range 3-84 years; SD 20.7), Considerably lower age group involvement has been reported by Olaniran Alabi ${ }^{8}$ et al where about three quarters 141 $(73 \%))$ of the victims were aged $<16$ year.

\section{Gender}

Males (53\%) were more involved in the mass casualties than females (Figure 2). This may be due to the fact that females were mainly doing indoor house hold activities and male use to travel for job as they are the earning group and often engaged with outdoor activities.

Delphin I. Muyila ${ }^{7}$ et al study 128 (66\%) were males;In Olaniran Alabi ${ }^{8}$ et al study $128(66 \%)$ were males and (56.7\%) were male in a study by Ni M Susilawathi ${ }^{9}$ et al .

\section{Injuries}

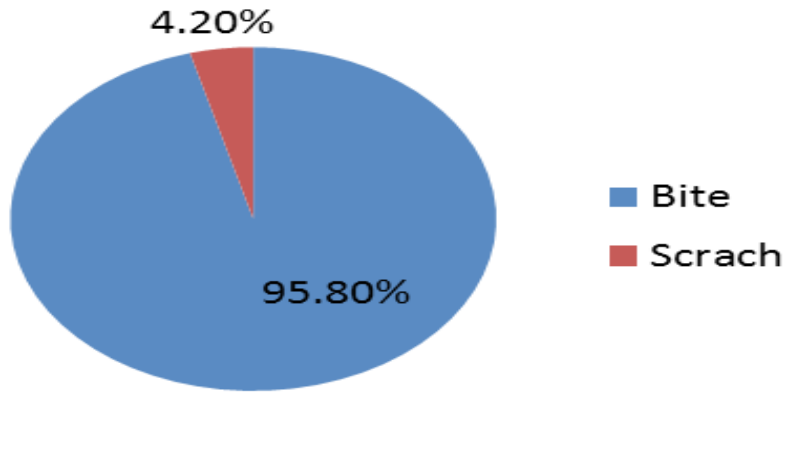

Figure 4: cause of injury.

Place

District wise analysis revealed that cases were mainly reported from Kozhikode district 79.2\%), followed by Malappuram (15.3\%), Kannur (4.2\%), and Palakkad (1.3\%). 82.2\% cases were from Rural area compared to $17.8 \%$ cases from urban area,suggestive of more stray dogs from rural area and similar finding was also seen in study by Ni M Susilawathi ${ }^{8}$ et al. Even though our institution caters to the above mentioned districts in addition to Kozhikode district, due to the availability of anti rabies vaccine and serum at all district hospitals in recent years a decrease in referrals from other districts have seen but only the most severe cases being referred to our institution.

\section{Time}

Maximum number of incidents were reported during the month of March (11 episodes) followed by December (8episodes), August (6 episodes), June and April (5 episodes each) and minimum number of incidents during May and July (1 episode each ) (Figure 1)

\section{Type of Animal}

Dogs were the main animal involved (77.1\%) followed by fox (11.1\%). Out of the dogs stray dogs were the majority as shown in Figure 3.

Delphin I. Muyila ${ }^{7}$ et al also showed dogs mainly stray dogs were the causative animal. A quarter, (26\%) of the dogs were unrestricted, (74\%) had owners as reported by Olaniran Alabi ${ }^{8}$ et al .

Even though most studies report dog as the biting animal in $90 \%$ of the cases these studies are not on mass casualty cases. The probability of mass bites are more among stray unimmunised dogs and wild animals as evidenced from our study

\section{Site of bite}

As shown in the (Table 2) the site of bite it was found that majority of bites were on lower limb (57.2\%), followed by upper limb(24.2\%), head 
\&neck ( $5.5 \%)$ and trunk (4.7\%). Bite on multiple sites effecting face, upper limb and lower limb were more common than single site injury. Multiple wounds on different site were seen in $64.8 \%$ of cases than single bite.

Delphin I. Muyila ${ }^{7}$ et al study site of bite were Legs (66.7\%), arms (23.8\%), and back (9.5\%) were the most frequently reported location of the bites. The majority, $165(85 \%))$ of the bites were on the hands. However, studies in the U.S. and South Africa have reported that the common anatomical site for dog bite injuries in children $>6$ years is to the lower limbs. ${ }^{10,11}$ Ni M Susilawathi ${ }^{9}$ et al study bites were most common in the lower extremities $(59.3 \%)$, followed by the upper extremities $(37.2 \%)$ and the head and neck (3.5\%). Single bite cases were more frequent $(72.9 \%)$ than multiple bite cases (27.1\%).

\section{Injuries}

Bite was the major reason for injury in $95.8 \%$ cases and followed by scratch in $4.2 \%$ cases and all wounds belongs to category III type.

The severity of the injuries and the fact that there were no cases of either Cat egory 2 or 1 cases indicates that exposures in mass casualty need immediate Post exposure treatment.

\section{Management of Wound}

All cases were Category III wounds and treated with both anti rabies vaccine (IDRV) and Anti Rabies Serum. 95.8\% patients were treated with Equine Rabies Immunoglobulin after obtaining a valid consent before doing a sensitivity test and those sensitive to ERIG were treated with $\mathrm{Hu}$ man Rabies Immunoglobulin (3.4\%). Serum administration was done maximum locally around the wound and rest in the gluteal region deep IM. Other supportive measures like general wound management, antibiotics, tetanus prophylaxis were given and surgery consultation were done for the severely bitten cases. Till the date no rabies cases have been reported from these incidents showing $100 \%$ prevention of rabies.

\section{Summary}

There were total of 7072 animal bite cases reported to the preventive clinic during this time period .Out of this, there were 54 incidents of mass casualty. In these 54 mass casualties, 236 patients were involved. Majority were males (53\%). Adults (74.2\%) were commonly affected than children (25.8\%). In this study, the minimum, maximum and median number of dog bite cases per dog registered in the Mass casualty Register was found to be 3,27 and 6 respectively .

Exposure to dogs constituted $77.1 \%$ of cases followed by fox $(11.9 \%)$, mongoose $(7.6 \%)$ and wild pig (3.4\%). Out of $77.1 \%$ dog exposure, majority (97\%) were stray dog exposure. Multiple wounds (64.8\%) were common than single site injury. Injuries in lower limb constituted (57.2\%), followed by upper limb (24.2\%), head and neck area (5.5\%). All were category III wounds and were given anti rabies vaccine ,immunoglobulin and antibiotics. Anti rabies vaccination is safe and fully effective.

\section{CONCLUSION}

There were 54 mass casualty incidents/year and 236 people were bitten by probable rabid animal. Most common animal involved were Dogs. Young adults were commonly affected. The bites in mass casualties are invariably severe bites belonging to Category III which require Immunoglobulin administration. Control of stray dog population is essential for bringing down their numbers and there by consequently bringing down the incidents of animal bites. Animal birth control along with mandatory vaccination of dog may be the long term solution needed to address the problem.

\section{Limitation of study}

As this is a record based crossectional study from a tertiary care institution some of the category I and category II cases may not be include as they are managed at local hospital.

\section{CONFLICT OF INTERESTS}

Nil

\section{REFERENCES}

1. Wiggins ME, Akelman E, Weiss APC. The management of dog bite and dog bite infection to the hand. Orthopedics.194;17(7):617-23.[PubMed]

2. WHO Expert Consultation on Rabies W H OT e c h n i c a I R e p ort S e ri es 982 second report

3. NATIONAL CENTRE FOR DISEASE CONTROL (Directorate General of Health Services) National Rabies Control Programme National Guidelines on Rabies Prophylaxis http://www.ncdc.gov.in 2015

4. Janie M. Baxter One in a million, or one in thousand: What is the morbidity of rabies in India? One in a million, or one in thousand: What is the morbidity of rabies in India? June 2012;2(1):010303

5. Sudarshan MK et al. Assessing the burden of human rabies in India: results of a national multi-center epidemiological survey. International Journal of Infectious Diseases. 2007;11(1):29-359.

6. Suraweera $W$ et al. Deaths from symptomatically identifiable furious rabies in India: a nationally representative mortality survey. PLoS Neglected Tropical Diseases. 2012;6(10):e1847.

7. Delphin. Muyila Michel N. Aloni, Marie Jose 'e Lose-Ekanga, Jules M. Nzita, Alexandre Kalala-Mbikay, Henri L. Bongo, Mathilde N. Esako, Jean Pierre Malonga-Biapi, Beno ^t Mputu-Dibwe, Muriel L. Aloni, Mathilde B. Ekila Human rabies: a descriptive observation of 21 children in Kinshasa, the Democratic Republic of Congo: Pathogens and Global Health 2014 VOL. 108 NO.7 317

8. Olaniran Alabi, Patrick N, Silvester C, Ayika G, Peter N. Joliath Umoh Profile of dog bite victims in Jos Plateau State, Nigeria: a review of dog bite records (2006-2008). Pan African Medical Journal. 2014;18(Supp 1):12 |

9. Susilawathi NM, Agus ED, Ida BNP D, Nyoman SB, Gusti A, Ketut S, et al. Epidemiological and clinical features of human rabies cases in Bali 2008-2010 Ni M Susilawathi1 BMC Infectious Diseases 2012, 12:81 http://www.biomedcentral. com/1471-2334/12/81

10. Sacks JJ, Sinclair L, Gilchrist J, Golab GC, Lockwood R. Special Report Breeds of dogs involved in fatal human attacks in the United States between 1979 and 1998. 2000;217

11. Sahu KK, Manar MK, Singh SK, Singh H. Epidemiological characteristics of patients attending for rabies post-exposure prophylaxis at the infectious diseases hospital of Lucknow, India. J Global Infect Dis [serial online] 2015 [cited 2015 Nov 23];7:30-2. Available from: http://www.jgid.org/text.asp?2015/7/1/30/150888

Cite this article : Ramakrishnan LV, Shakir L, Chandran P, Thavody J. Profile of Mass Casualties of Animal Bite Cases Reported to a Tertiary Care Institution from April 2014 to March 2015 in North Kerala : India. Int J Med. Public Health. 2017; 7(1): 33-7 